\title{
BMJ Open \\ Maternal pre-pregnancy weight and externalising behaviour problems in preschool children: a UK-based twin study
}

\author{
Evangelia E Antoniou, ${ }^{1}$ Tom Fowler, ${ }^{2}$ Keith Reed, ${ }^{3}$ Taunton R Southwood, ${ }^{4}$ \\ Joseph P McCleery, ${ }^{5,6}$ Maurice P Zeegers ${ }^{7}$
}

To cite: Antoniou EE, Fowler T, Reed K, et al. Maternal pre-pregnancy weight and externalising behaviour problems in preschool children: a UKbased twin study. BMJ Open 2014:4:e005974. doi:10.1136/bmjopen-2014005974

- Prepublication history for this paper is available online. To view these files please visit the journal online (http://dx.doi.org/10.1136/ bmjopen-2014-005974).

Received 25 June 2014 Revised 19 August 2014 Accepted 27 August 2014

CrossMark

For numbered affiliations see end of article.

Correspondence to Dr Evangelia E Antoniou; eva.antoniou@ maastrichtuniversity.nl

\section{ABSTRACT}

Objective: To estimate the heritability of child behaviour problems and investigate the association between maternal pre-pregnancy overweight and child behaviour problems in a genetically sensitive design.

Design: Observational cross-sectional study.

Setting: The Twins and Multiple Births Association Heritability Study (TAMBAHS) is an online UK-wide volunteer-based study investigating the development of twins from birth until 5 years of age.

Participants: A total of 443 (16\% of the initial registered members) mothers answered questions on pre-pregnancy weight and their twins' internalising and externalising problems using the Child Behavior Checklist and correcting for important covariates including gestational age, twins' birth weight, age and sex, mother's educational level and smoking (before, during and after pregnancy).

Primary outcomes: The heritability of behaviour problems and their association with maternal prepregnancy weight.

Results: The genetic analysis suggested that genetic and common environmental factors account for most of the variation in externalising disorders (an ACE model was the most parsimonious with genetic factors $(A)$ explaining $46 \%(95 \% \mathrm{Cl} 33 \%$ to $60 \%)$ of the variance, common environment $(\mathrm{C})$ explaining $42 \%$ (95\% Cl $27 \%$ to $54 \%$ ) and non-shared environmental factors (E) explaining $13 \%(95 \% \mathrm{Cl}$ $10 \%$ to $16 \%$ ) of the variance. For internalising problems, a CE model was the most parsimonious model with the common environment explaining $51 \%$ (95\% Cl $44 \%$ to $58 \%$ ) of the variance and nonshared environment explaining $49 \%$ (95\% Cl $42 \%$ to $56 \%$ ) of the variance. Moreover, the regression analysis results suggested that children of overweight mothers showed a trend $(\mathrm{OR}=1.10,95 \% \mathrm{Cl} 0.58 \%$ to 2.06) towards being more aggressive and exhibit externalising behaviours compared to children of normal weight mothers.

Conclusions: Maternal pre-pregnancy weight may play a role in children's aggressive behaviour.

\section{Strengths and limitations of this study}

- In the twin genetic design, maternal prepregnancy weight was included in the genetic model, in order to investigate the influence of the intrauterine environment on children's behaviour problems.

- Cut-off scores applied to the child behaviour scale enabled us to clinically assess the observed association.

- A number of covariates of post-natal influence were adjusted such as maternal educational level and smoking after pregnancy.

- Information on other parental characteristics such as maternal psychopathology and personality was not available.

\section{INTRODUCTION}

The preschool years of a child are generally considered important, since during this period many clinically significant problem behaviours may occur. ${ }^{2}$ Externalising (eg, aggression, conduct problems, hyperactivity) and internalising problems (eg, emotional problems, anxiety, depression) can often be identified first in early childhood, which then shows considerable stability across older ages. $^{3-5}$ Toddlers with problem behaviours are at risk for a variety of adverse developmental outcomes including conflictual relationships with other peers or family, poor academic performance, delinquency and later maladjustment. ${ }^{6-8}$ Given the life course implications of early onset symptomatology, it is essential to understand the underlying aetiology of problem behaviours in preschool children.

Twin studies investigating externalising and internalising problems have revealed substantial genetic influence, with heritabilities ranging from $40-70 \%$ in these age groups. ${ }^{9-11}$ 
The influence of the shared environment is, however, more modest, explaining up to $40 \%$ of the variance in behaviour problems. ${ }^{9-12}$

Since the 1990s, there has been an increased interest in the research of the effect of the intrauterine environmental and maternal well-being during pregnancy on later child development. Epidemiological studies suggest strong links between measures of the quality of the prenatal environment and the risk of cardiovascular and metabolic diseases, ${ }^{13} 14$ and more research evidence suggests that low birth weight can be linked with impaired cognitive development and behavioural disorders, especially hyperactivity/inattention, ${ }^{15} 16$ while several studies have examined the association between low birth weight and internalising and externalising behaviours. ${ }^{17-19}$

Research findings ${ }^{20-23}$ suggest that another intrauterine factor, maternal pre-pregnancy obesity/weight, is associated with reduced cognitive abilities, symptoms of inattention and negative emotionality in school aged children. These findings are of clinical importance, especially in the light of the increasing prevalence of obese women entering pregnancy. ${ }^{24}$ Pregnancy comes with main changes in the maternal body and a high prepregnancy weight is more likely to make these adaptations even more difficult, affecting child development. With the exception of one recent study ${ }^{25}$ suggesting that fetal exposure to increased maternal body mass index (BMI) is associated with elevated levels of externalising problems in 2-year-old children, not much is known about the influence of maternal pre-pregnancy weight on externalising and internalising behaviour problems in young age groups after that age and before the age of 5. By implementing a twin research design including maternal pre-pregnancy weight in the genetic model, we set out to investigate the role of the intrauterine, common and genetic environment on children's behaviour problems.

\section{METHODS}

The Twins and Multiple Births Association Heritability Study (TAMBAHS) is a volunteer-based study, investigating the development of twins from birth until 5 years of age. An invitation letter to this study was sent to all present $(n=2712)$, at the moment of the study, twin family registered members of the Twins and Multiple Births Association (TAMBA) beginning of July 2008. TAMBA is an association, which registers and provides support to multiple birth families across the UK. Mothers of twins aged between 18 months and 5 years at the time of the survey were identified. In the time period between July 2008 and May 2010, 443 (16\%) mothers completed the study's online questionnaire on their twins' emotional and behavioural development. The participants show a similar and representative geographical spread of the twin families across the UK. All mothers consented before participating.

\section{Zygosity determination}

For the determination of the twins' zygosity, the previously adapted version of Goldsmith's zygosity questionnaire was used. ${ }^{26}$ This questionnaire method of assigning zygosity has been validated against determination by identity of polymorphic DNA markers and has reached accuracy in verifying zygosity in $95 \%$ of the cases. ${ }^{27}$

\section{Twin sample}

In total, 443 twin pairs were included in the analyses; 186 monozygotic (MZ) male twins, $138 \mathrm{MZ}$ female twins, 144 dizygotic (DZ) male twins, $158 \mathrm{DZ}$ female twins and 260 opposite-sex twins.

\section{MATERIALS}

\section{Maternal pre-pregnancy weight and covariates}

The primary exposure variable was maternal pre-pregnancy BMI. Pre-pregnancy BMI was based on the maternal selfreport of weight and height and was calculated by dividing their weight in kilograms by their self-report height in metres squared $\left((\mathrm{kg}) /\right.$ height $\left.\left(\mathrm{m}^{2}\right)\right)$. Pre-pregnancy BMI was analysed both as a continuous and as a categorical variable and was classified according to the WHO standard guidelines as: underweight $(<18.5 \mathrm{~kg})$, normal weight $(18.5-24.99 \mathrm{~kg})$, overweight/obese $(\geq 25 \mathrm{~kg})$. Overweight and obese mothers were combined in one category due to the limited number of obese mothers.

Gestational age (measured in completed weeks of gestation), educational level and smoking (before, during and after pregnancy) were noted for mothers; age, sex and birth weight were noted for all twins.

\section{The Child Behavior Checklist (CBCL/1 $1 \frac{1}{2 y-5 y)}$}

The Child Behavior Checklist for toddlers (CBCL/ $11 / 2-5)^{28}$ is used to obtain standardised parent reports of children's problem behaviours. It contains 99 problem items, split into 7 subcategories: emotionally reactive, anxious/depressed, somatic symptoms, withdrawn, sleep problems, attention problems and aggressive behaviour originally derived by factor analyses. ${ }^{28}$ The broadband scale 'Internalizing' is the sum score of items in the first four syndrome scales, whereas 'Externalizing' is the sum score of attention problems and aggressive behaviour. 'Total problems' is the sum score of all ninety-nine problem items. Each item is scored $0=$ not true, $1=$ somewhat or sometimes true, and 2=very true or often true, based on the preceding 2 months. Good reliability and validity criteria have been reported for this checklist. ${ }^{28}$ To identify children who may be above the normal range for the syndrome scales, children were categorised as being in the normal range when their $\mathrm{T}$ scores were below 65 (or the 93rd centile) and as being in the borderline/clinical range when their $\mathrm{T}$ scores $\geq 65$ (or the 97th centile) ${ }^{28}$ For internalising, externalising and total problem broadband scales, the cut-off point used for the normal range was a $\mathrm{T}$ score $<60$, and borderline/clinical $\geq 60$. The selection of lower cut-off scores for the 
broadband scales was based on the notion that these scales encompass more numerous and diverse problems than any of the syndrome scales, with the latter comprising smaller, more homogeneous sets of problems. Therefore, higher scores are needed for the syndrome scales in order to conclude that a behaviour is clinically deviant (ref. 28, p.1392).

\section{Statistical analysis}

Correlations

Intrapair twin correlations were calculated by using Pearson's (r) and Spearman's rho coefficient statistics as appropriate to explore the genetic and environmental influences.

\section{Heritability analysis}

Univariate genetic models were fit to the data in order to estimate the heritability of the problem scales using a maximum likelihood approach implemented in Mx. ${ }^{29}$ The classical twin study design relies on studying twins raised in the same family environments. MZ twins share all of their genes, while DZ twins share only about half of them. So if a researcher compares the similarity between sets of identical twins to the similarity between sets of fraternal twins for a particular trait, then any excess likeness between the identical twins should be due to genes (ie, the A component in a genetic model fitting) rather than environment. Researchers use this method, and variations on it, to estimate the heritability of traits: the proportion of variance in a population explained by genes. Modern twin studies also try to quantify the effect of a person's common environment (family, ie, the $\mathrm{C}$ component in a genetic model fitting) and non-shared environment (the individual events that shape a life, ie, the $\mathrm{E}$ component in a genetic model fitting) on a trait.

The estimates of the heritability are presented with 95\% CIs and goodness of fit statistics for several models: a full ACE model, in which the phenotypic variance is explained by genetic (A) common environmental factors (C) and non-shared (E) environmental factors. Reduced models were estimated by removing one of the parameters at a time and rerunning the model. The goodness of fit of the reduced models was compared to the full model to assess whether they represented a better explanation of the data using the likelihood ratio $\chi^{2}$ test and the Akaike Information Criterion (AIC). The models were assessed by examining the decrease in the fit of the model; if a parameter could be dropped without a significant decrease in fit, then on the grounds of parsimony the reduced model was accepted as the best fitting model. Models were fit both unadjusted and adjusted for pre-pregnancy maternal weight.

\section{Regression analyses}

Effects on a continuous scale

Standardised coefficients ( $\beta$ s) are presented, reflecting the change on the subcategories and the broadband problem scales by a change in the mother's weight, both expressed as SD change.

\section{Effects on clinically important behaviour problems}

In order to estimate the effect of the different categories of maternal weight on clinical problems, logistic regression models were fitted. In these models, the intercept of each twin pair was modelled as a function of the population intercept plus the individual contribution of the twin pair. Associations of maternal pre-pregnancy weight and the syndrome and broadband scales were explored unadjusted and adjusted for twins' sex, age, birth weight, gestational age, maternal smoking (before, during and after pregnancy) and maternal educational level. All analyses were performed in STATA V. $11{ }^{30}$

\section{RESULTS}

\section{Correlations}

The means for the three broadband scales and the intrapair twin correlations for MZ and DZ twins were calculated (table 1). For externalising problems, the MZ correlation was $\mathrm{r}=0.89$ and the $\mathrm{DZ}$ correlation was $\mathrm{r}=0.62$. For internalising problems, the MZ and DZ correlations were $r=0.81$ and $r=0.56$, respectively. For Total problems, the MZ and DZ correlations were $\mathrm{r}=0.92$ and $\mathrm{r}=0.75$, respectively.

\section{Heritability analyses}

Variance estimates of ACE models and submodels with their $95 \%$ CI are presented in table 2, in which the most parsimonious model is highlighted. For externalising problems, an ACE model was the most parsimonious with genetic factors explaining $46 \%$ (95\% CI 33\% to $60 \%$ ) of the variance, common environment explaining $42 \%(95 \%$ CI $27 \%$ to $54 \%)$ and non-shared environmental factors explaining $13 \%$ (95\% CI $10 \%$ to $16 \%$ ) of the variance. For internalising problems, a CE model was the most parsimonious with common environment explaining $51 \%(95 \%$ CI $44 \%$ to $58 \%)$ of the variance and non-shared environment explaining $49 \%$ (95\% CI $42 \%$ to $56 \%$ ) of the variance. For total problems, an ACE model was the most parsimonious with genetic factors explaining $26 \%$ (95\% CI $13 \%$ to $39 \%$ ) of the variance, common environment explaining $61 \%(95 \%$ CI $49 \%$ to $70 \%$ ) of the variance and non-shared environment explaining $13 \%$ (95\% CI $10 \%$ to $17 \%$ ) of the variance.

After adjusting for maternal pre-pregnancy weight, the most parsimonious model for externalising problems was the ACE model with genetic factors explaining $50 \%$ (95\% CI $36 \%$ to $68 \%$ ), common environment explaining $38 \%$ (95\% CI $20 \%$ to $52 \%$ ) and non-shared environment explaining $12 \%$ (95\% CI $0.09 \%$ to $16 \%$ ) of the variance. For Internalising problems, the most parsimonious model was the $\mathrm{AE}$ model with genetic factors explaining 59\% (95\%: $50 \%$ to $67 \%$ ) and non-shared environment explaining $41 \%$ (95\% CI $33 \%$ to $50 \%$ ) of 
Table 1 Descriptive statistics of problem broadband scales for monozygotic and dizygotic twin pairs

\begin{tabular}{|c|c|c|c|c|c|c|c|c|c|c|c|c|c|c|}
\hline \multirow[b]{3}{*}{ Problem scales } & \multicolumn{6}{|c|}{ Monozygotic twin pairs } & \multirow[b]{3}{*}{$\mathbf{r}$} & \multicolumn{7}{|c|}{ Dizygotic twin pairs } \\
\hline & \multicolumn{3}{|c|}{ Twin 1} & \multicolumn{3}{|c|}{ Twin 2} & & \multicolumn{3}{|c|}{ Twin 1} & \multicolumn{3}{|c|}{ Twin 2} & \multirow[b]{2}{*}{$\mathbf{r}$} \\
\hline & $\mathbf{N}$ & $\mathbf{M}$ & SD & $\mathbf{N}$ & $\mathbf{M}$ & SD & & $\mathbf{N}$ & M & SD & $\mathbf{N}$ & $\mathbf{M}$ & SD & \\
\hline Externalising (range 0-48) & 167 & 12.88 & 7.72 & 167 & 12.83 & 7.51 & 0.89 & 269 & 12.79 & 6.61 & 269 & 12.66 & 6.95 & 0.62 \\
\hline Internalising (range 0-96) & 167 & 5.94 & 4.55 & 167 & 9.13 & 6.98 & 0.81 & 269 & 5.49 & 4.11 & 269 & 8.24 & 5.89 & 0.56 \\
\hline Total problems (range 0-78) & 167 & 31.58 & 16.24 & 167 & 34.66 & 18.90 & 0.92 & 269 & 30.45 & 14.18 & 269 & 33.06 & 16.10 & 0.75 \\
\hline
\end{tabular}

the variance. For Total problems, the most parsimonious model was the ACE model with genetic factors explaining $25 \%$ (95\% CI $14 \%$ to $38 \%$ ), common environment explaining $62 \%$ (95\% CI $49 \%$ to $72 \%$ ) and non-shared environment explaining $13 \%$ (95\% CI $0.10 \%$ to $17 \%$ ) of the variance.

The mean maternal BMI, gestational age, age and sex of the twins stratified by zygosity are presented in table 3. There were no differences in maternal weight between MZ and DZ twins. However, differences were observed between MZ and DZ twins with regard to their age and gestational age. Mothers of DZ twins had a higher gestational age (36.22, 95\% CI $36.00 \%$ to 36.43 , $\mathrm{p}<0.001)$ compared to mothers of $\mathrm{MZ}$ twins $(35.24,95 \%$ CI $35.12 \%$ to 36.43$)$; the MZ twins were older (3.13 years old, $95 \%$ CI $3.03 \%$ to $3.23, \mathrm{p}<0.001$ ) compared to the DZ twins (2.91 years old, 95\% CI $2.83 \%$ to 2.98). Correlations of maternal and twin covariates and problem broadband scales are also presented in the same table.

\section{Regression analyses}

In the adjusted model (table 4), there was a significant increase of 0.08 SDs in aggressive behaviour with every SD increase in maternal weight $(p=0.02)$. The logistic regression analysis partly confirmed these findings. Overweight mothers were 1.10 times more likely to have a child with clinically aggressive behaviour when compared to normal weight mothers and 0.78 times more likely when compared to underweight mothers. The individual OR did not reach statistical significance; a trend, however, $(\mathrm{OR}=1.10,95 \% \mathrm{CI} 0.58 \%$ to $2.06 \%)$ is observed for children of overweight mothers to show clinically aggressive behaviour.

Similarly, there was an increase of 0.09 SDs $(p=0.02)$ in externalising problems with every SD increase in maternal weight. An increase in the likelihood of externalising ( $\mathrm{OR}=1.32,95 \%$ CI $0.84 \%$ to 2.05$)$ for children with overweight mothers compared to children of normal weight mothers was also apparent. No other statistically significant associations between maternal prepregnancy weight and behaviour problems were observed.

\section{DISCUSSION}

In this study, the effect of maternal pre-pregnancy weight on problem behaviours and the influence of genetic and environmental factors on these problems were investigated. The heritability analysis suggested that genetic and common environmental factors account for most of the variation in externalising disorders, while common and non-shared environment explain most of the variation in internalising disorders. After adjusting for mothers' weight, there was a non-significant decrease (of $2 \%$ ) of variation in externalising problems that

Table 2 Univariate genetic model-fitting for the problem scales presenting full and nested models

\begin{tabular}{|c|c|c|c|c|c|c|}
\hline & A (95\% Cl) & C (95\% Cl) & $\mathrm{E}(95 \% \mathrm{Cl})$ & $\Delta \mathrm{x}^{2}$ & p Value & AIC \\
\hline \multicolumn{7}{|c|}{ Externalising } \\
\hline ACE* & 0.46 (0.33 to 0.60$)$ & $0.42(0.27$ to 0.54$)$ & $0.13(0.10$ to 0.016$)$ & - & - & - \\
\hline $\mathrm{AE}$ & 0.87 (0.84 to 0.90$)$ & (0) & $0.13(0.10$ to 0.16$)$ & 23.44 & 0.00 & 21.44 \\
\hline CE & (0) & 0.74 (0.69 to 0.78 ) & $0.26(0.22$ to 0.31$)$ & 49.69 & 0.00 & 47.69 \\
\hline \multicolumn{7}{|c|}{ Internalising } \\
\hline ACE & 0.23 (0.00 to 0.48 ) & 0.35 (0.12 to 0.54$)$ & $0.43(0.35$ to 0.53$)$ & - & - & - \\
\hline $\mathrm{AE}$ & $0.60(0.52-0.67)$ & (0) & 0.40 (0.33 to 0.48$)$ & 8.84 & 0.00 & 6.84 \\
\hline$C E^{\star}$ & (0) & 0.51 (0.44 to 0.58 ) & 0.49 (0.42 to 0.56$)$ & 3.15 & 0.07 & 1.15 \\
\hline \multicolumn{7}{|c|}{ Total problems } \\
\hline ACE* & 0.26 (0.16 to 0.39$)$ & 0.61 (0.49 to 0.70$)$ & $0.13(0.10$ to 0.17$)$ & - & - & - \\
\hline $\mathrm{AE}$ & 0.87 (0.84 to 0.90$)$ & (0) & $0.13(0.10$ to 0.16$)$ & 53.64 & 0.00 & 51.64 \\
\hline CE & (0) & 0.79 (0.76 to 0.83 ) & $0.21(0.17$ to 0.24$)$ & 22.17 & 0.00 & 20.17 \\
\hline
\end{tabular}

*Best fitting model.

A, additive genetic; AIC, Akaike's Information Criterion; C, shared environment; $E$, non-shared environment; $P$, statistical significance $<0.05$; $\Delta \chi^{2}$, difference $\chi^{2}$. 


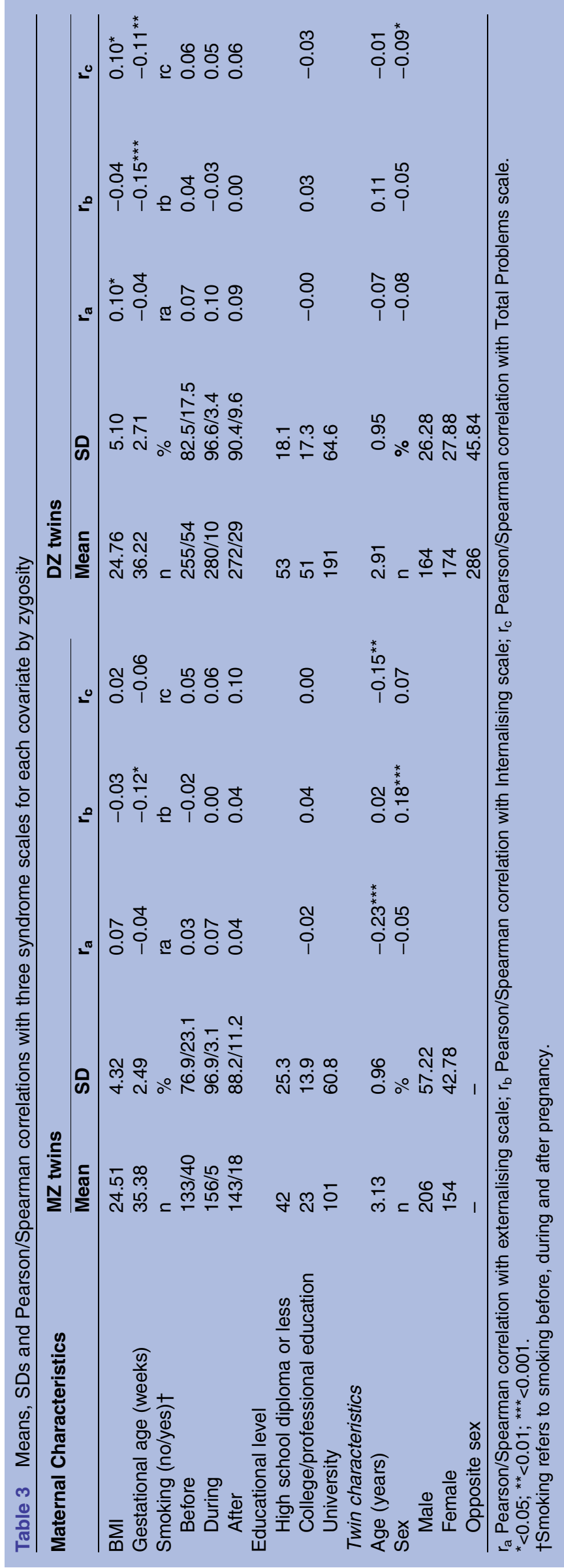

could be explained by the common environment, suggesting that mothers' weight may play an important role in explaining externalising problems. In order to further explore the role of overweight in externalising problems, we repeated the analysis by comparing the twins of overweight mothers to the twins of normal weight mothers. The results suggested that $50 \%$ (CI's $29 \%$ to $67 \%$ ) of the variation in externalising problem behaviour in twins of overweight mothers could be explained by common environment compared to $35 \%$ (CI's $10 \%$ to $53 \%$ ) in twins of normal weight mothers.

In general, the results showed that children of overweight mothers showed a trend towards being more aggressive and exhibit externalising behaviours compared to children of normal weight mothers. Aggressive behaviour is considered an important aspect of externalising behaviour and has developmentally been linked to antisocial behaviour. ${ }^{31}{ }^{32}$ Studies with children focusing on aggression have shown that observed aggression and parental reports of externalising behaviours are relatively stable from toddlerhood to 5 years and beyond, ${ }^{1}{ }^{33}$ which may highlight the role of genetic influences. Consistent with this are the results of this study, which suggest that genetic factors can explain a large part of the variation in externalising and internalising behaviour problems.

The results from the logistic regression, however, do not suggest a strong association between maternal overweight and behaviour problems. Moreover, the significantly observed change in the standardised coefficients could not explain the distinction between normal range and borderline/clinical range. Therefore, children appeared to be more aggressive, but it is not clear whether this is of clinical significance.

Two studies by Rodriguez and colleagues ${ }^{20} 21$ suggested a link between pre-pregnancy overweight and obesity and symptoms of ADHD in children. In both studies, teacher ratings of the offspring of obese mothers had increased levels of ADHD. However, in the latter study, parent reports of childhood ADHD symptoms and negative emotionality failed to support a link. While this could mean that the effect may be small, in the light of the low to moderate associations seen between parent and teacher ratings of children's ADHD, one cannot rule out a link. A recent study by Van Lieshout $e t a P^{34}$ showed that increased maternal prepregnancy BMI was associated with higher levels of externalising problems at age 2. However, in that study, authors did not correct for maternal or paternal psychopathology, or maternal personality traits. Similarly, in our study, we may not be able to strongly establish a causal link between pre-pregnancy weight and aggressive/externalising problems, but by applying clinically relevant cut-off points in the measurement tool of child behaviour, we suggest that there may be a trend for more aggressive behaviours from children of obese mothers. As has been previously suggested, ${ }^{23}$ future studies could benefit from the utilisation of genetically 
Table 4 Logistic and linear regression for children's behavioural problems based on maternal BMI†

\begin{tabular}{|c|c|c|c|c|c|c|c|c|c|c|}
\hline & Behavioural problems $¥$ & No behavioural problems $¥$ & OR & $95 \% \mathrm{Cl}$ & $\boldsymbol{\beta}$ & p Value & ORt & $95 \% \mathrm{Cl}$ & $\boldsymbol{\beta}$ & p Value \\
\hline Emotional reactivity & $\mathrm{N}$ & $\mathrm{N}$ & & & 0.03 & 0.42 & & & 0.02 & 0.58 \\
\hline Underweight & 6 & 82 & 1.10 & 0.44 to 2.77 & & & 1.12 & 0.42 to 2.96 & & \\
\hline Normal weight & 25 & 376 & 1.00 & Reference & & & 1.00 & Reference & & \\
\hline Overweight/obese & 20 & 283 & 1.06 & 0.58 to 1.95 & & & 1.05 & 0.54 to 2.06 & & \\
\hline Anxiety/depression & $\mathrm{N}$ & $\mathrm{N}$ & & & -0.03 & 0.40 & & & -0.02 & 0.62 \\
\hline Underweight & 5 & 83 & 0.77 & 0.29 to 2.06 & & & 0.86 & 0.31 to 2.41 & & \\
\hline Normal weight & 29 & 372 & 1.00 & Reference & & & 1.00 & Reference & & \\
\hline Overweight/Obese & 14 & 289 & 0.62 & 0.32 to 1.20 & & & .65 & 0.32 to 1.30 & & \\
\hline Somatic symptoms & $\mathrm{N}$ & $\mathrm{N}$ & & & -0.01 & 0.11 & & & -0.07 & 0.07 \\
\hline Underweight & 11 & 77 & 1.33 & 0.65 to 2.70 & & & 0.99 & 0.43 to 2.26 & & \\
\hline Normal weight & 39 & 362 & 1.00 & Reference & & & 1.00 & Reference & & \\
\hline Overweight/obese & 30 & 273 & 1.02 & 0.62 to 1.68 & & & 0.99 & 0.56 to 1.75 & & \\
\hline Withdrawn behaviour & $\mathrm{N}$ & $\mathrm{N}$ & & & -0.06 & 0.09 & & & -0.02 & 0.58 \\
\hline Underweight & 3 & 85 & 1.14 & 0.32 to 4.14 & & & 1.53 & 0.36 to 6.61 & & \\
\hline Normal weight & 12 & 389 & 1.00 & Reference & & & 1.00 & Reference & & \\
\hline Overweight/obese & 14 & 289 & 1.57 & 0.72 to 3.45 & & & 2.66 & 0.99 to 7.09 & & \\
\hline Attention & $\mathrm{N}$ & $\mathrm{N}$ & & & 0.06 & 0.08 & & & 0.03 & 0.39 \\
\hline Underweight & 5 & 83 & 0.74 & 0.28 to 1.98 & & & 1.17 & 0.42 to 3.29 & & \\
\hline Normal weight & 30 & 371 & 1.00 & Reference & & & 1.00 & Reference & & \\
\hline Overweight/Obese & 29 & 274 & 1.31 & 0.77 to 2.23 & & & 1.13 & 0.60 to 2.13 & & \\
\hline Aggressive behaviour & $\mathrm{N}$ & $\mathrm{N}$ & & & 0.08 & $0.02^{*}$ & & & 0.07 & 0.07 \\
\hline Underweight & 4 & 84 & 0.78 & 0.26 to 2.32 & & & .87 & 0.28 to 2.69 & & \\
\hline Normal weight & 23 & 378 & 1.00 & Reference & & & 1.00 & Reference & & \\
\hline Overweight/obese & 19 & 284 & 1.10 & 0.58 to 2.06 & & & 1.04 & 0.52 to 2.10 & & \\
\hline Sleeping problems & $\mathrm{N}$ & $\mathrm{N}$ & & & 0.06 & 0.11 & & & 0.03 & 0.48 \\
\hline Normal weight & 14 & 387 & 1.00 & Reference & & & 1.00 & Reference & & \\
\hline Underweight & 3 & 85 & 0.98 & 0.27 to 3.47 & & & 0.97 & 0.20 to 4.66 & & \\
\hline Overweight/obese & 11 & 292 & 1.04 & 0.47 to 2.33 & & & 0.92 & 0.37 to 2.29 & & \\
\hline Externalising & $\mathrm{N}$ & $\mathrm{N}$ & & & 0.09 & $0.02^{*}$ & & & 0.07 & 0.08 \\
\hline Underweight & 6 & 81 & 0.56 & 0.23 to 1.36 & & & .66 & 0.26 to 1.66 & & \\
\hline Normal weight & 46 & 348 & 1.00 & Reference & & & 1.00 & Reference & & \\
\hline Overweight/obese & 44 & 253 & 1.32 & 0.84 to 2.05 & & & 1.17 & .69 to 1.99 & & \\
\hline Internalising & $\mathrm{N}$ & $\mathrm{N}$ & & & -0.04 & 0.29 & & & -0.03 & 0.44 \\
\hline Underweight & 16 & 72 & 1.85 & 0.99 to 3.46 & & & 1.86 & 0.93 to 3.73 & & \\
\hline Normal weight & 43 & 358 & 1.00 & Reference & & & 1.00 & Reference & & \\
\hline Overweight/obese & 34 & 269 & 1.05 & 0.65 to 1.70 & & & 1.01 & 0.59 to 1.74 & & \\
\hline Total problems & $\mathrm{N}$ & $\mathrm{N}$ & & & 0.07 & 0.05 & & & 0.06 & 0.14 \\
\hline Underweight & 6 & 82 & 0.59 & 0.24 to 1.43 & & & 0.59 & 0.23 to 1.50 & & \\
\hline Normal weight & 44 & 355 & 1.00 & Reference & & & 1.00 & Reference & & \\
\hline Overweight/obese & 41 & 260 & 1.27 & 0.81 to 2.00 & & & 1.18 & 0.70 to 2.00 & & \\
\hline
\end{tabular}

*<0.05.

†Adjusted for gestational age, twins' birth weight, age and sex, mother's educational level, smoking (before, during and after pregnancy).

$\neq$ Categorised based on children within normal range and borderline/clinical range. 
sensitive designs; in this study, we included prepregnancy weight in the genetic model and showed that there could be some intrauterine influence. Indeed, when we added pre-pregnancy weight in the genetic model, we observed a non-significant decrease in the variation of externalising problems explained by the common environment. This suggests that pre-pregnancy weight as an intrauterine factor may play an important role in the development of externalising problems.

A number of mechanisms could be responsible for the links between maternal obesity and neurodevelopmental problems in young children. The potential role of nutrition on the development of the brain has been investigated in the past. Although there is no clear pathway that links externalising problems to maternal overweight, several pathways have been proposed to explain this association and parallels between overweight and other developmental disorders can be drawn. Leptin, which is the protein produced by adipose cells, has been found to play multiple functions in reproduction, ${ }^{35}{ }^{36}$ glucose homoeostasis $^{37} 38$ as well as in brain ${ }^{39} 40$ and neurocognitive development. ${ }^{41}$ Another possible causal pathway suggests that pre-pregnancy overweight women may not be able to synthesise vitamin $\mathrm{D}$, due to the excessive adipose tissue, which results in deficiency in both the mother and the neonate; in turn, vitamin D is associated with neurocognitive function. ${ }^{42}$ In addition, high glucose levels pose a risk for neurobehavioural impairments. ${ }^{43}$ Moreover, epigenetic mechanisms affecting the central nervous system dopamine signalling could be a mechanism by which exposure to elevated maternal BMI during pregnancy might increase levels of externalising behaviour in children. ${ }^{4}$

However, others have emphasised the importance of the dynamics within the family environment, such as the parent-child interaction and the individual differences in parenting ${ }^{4546}$ and their impact on the course of the developmental pathways of problem behaviours. Previous research has mainly linked externalising problems with family adversity, maternal depression and low socioeconomic status. 3745

In addition, there may be other environmental factors, which it was not possible to examine in this study, that could accentuate these symptoms. For instance, parents with children displaying symptoms of aggressive behaviours normally report higher levels of stress and frequent use of negative parenting strategies, ${ }^{48}$ while it has been found that stress levels could be associated with weight gain. ${ }^{49}$ Thus, parental behaviour may fuel noncompliance, aggression and poor regulation of emotion, rather than providing toddlers adaptive models of regulated and pro-social functioning. ${ }^{50}$

The current study has a number of strengths including the use of a validated measure of childhood behaviour problems for children older in age than was previously used in the literature, and utilised a genetically sensitive design to assess the influence of maternal pre-pregnancy weight.
Moreover, compared to previous studies, ${ }^{20} 44$ we applied cut-off scores to the child behaviour scale, which enabled us to clinically assess the observed association. In addition, we were able to adjust for a number of covariates, which could indicate a post-natal influence on externalising behaviour, such as maternal educational level and smoking after pregnancy. However, we did not have information on other parental characteristics such as maternal psychopathology and personality.

To sum up, these results suggest a possible association between aggressive/externalising problems and maternal overweight. It is important, however, to keep in mind when conducting research with preschoolers that the investigation of children, who may be at risk for externalising problems, may pose the challenge of differentiating between age-related and normative levels of this behaviour from more serious early-emerging problems. ${ }^{51}$

\section{Author affiliations}

${ }^{1}$ Department of Clinical Psychological Science, Faculty of Psychology and Neuroscience, Maastricht University, Maastricht, The Netherlands

${ }^{2}$ Department of Public Health, Heart of Birmingham Teaching PCT,

Birmingham, UK

${ }^{3}$ The Twins and Multiple Births Association (TAMBA), UK

${ }^{4}$ Institute of Child Health, University of Birmingham, UK

${ }^{5}$ School of Psychology, University of Birmingham, UK

${ }^{6}$ Center for Autism Research, Children's Hospital of Philadelphia, Philadelphia,

PA USA

${ }^{7}$ Department of Complex Genetics, Cluster of Genetics and Cell Biology, NUTRIM School for Nutrition, Toxicology and Metabolism, Maastricht University Medical Centre, Maastricht, The Netherlands

Acknowledgements The authors would like to thank all participating families. Contributors EEA contributed to the conception and design, acquisition of the data, analysis and interpretation of the data and drafting of the manuscript. TF, KR, TRS, JPM and MPZ contributed to the conception, design and interpretation of the data. All authors critically revised the manuscript for important intellectual content, agreed to be accountable for all aspects of the work and approved the final manuscript.

Funding This study was funded by the University of Birmingham, UK. Competing interests None.

Ethics approval The study was approved by the ethics committee of the University of Birmingham

Provenance and peer review Not commissioned; externally peer reviewed.

Data sharing statement No additional data are available.

Open Access This is an Open Access article distributed in accordance with the Creative Commons Attribution Non Commercial (CC BY-NC 4.0) license, which permits others to distribute, remix, adapt, build upon this work noncommercially, and license their derivative works on different terms, provided the original work is properly cited and the use is non-commercial. See: http:// creativecommons.org/licenses/by-nc/4.0/

\section{REFERENCES}

1. Keenan K, Wakschlag LS. Can a valid diagnosis of disruptive behavior disorder be made in preschool children? Am J Psychiatry 2002;159:351-8.

2. Skovgaard AM, Houmann T, Christiansen E, et al. The prevalence of mental health problems in children 1(1/2) years of age-the Copenhagen Child Cohort 2000. J Child Psychol Psychiatry 2007;48:62-70. 
3. Briggs-Gowan MJ, Carter AS, Bosson-Heenan J, et al. Are infant-toddler social-emotional and behavioral problems transient? J Am Acad Child Adolesc Psychiatry 2006;45:849-58.

4. Mathiesen KS, Sanson A. Dimensions of early childhood behavior problems: stability and predictors of change from 18 to 30 months. $J$ Abnorm Child Psychol 2000;28:15-31.

5. Campbell SB, Pierce EW, March CL, et al. Hard-to-manage preschool boys: symptomatic behavior across contexts and time. Child Dev 1994;65:836-51.

6. Hofstra MB, van der Ende J, Verhulst FC. Child and adolescent problems predict DSM-IV disorders in adulthood: a 14-year follow-up of a Dutch epidemiological sample. J Am Acad Child Adolesc Psychiatry 2002;41:182-9.

7. Caspi A, Moffitt TE, Newman DL, et al. Behavioral observations at age 3 years predict adult psychiatric disorders. Longitudinal evidence from a birth cohort. Arch Gen Psychiatry 1996;53:1033-9.

8. Stevenson J, Goodman R. Association between behaviour at age 3 years and adult criminality. Br J Psychiatry 2001;179:197-202.

9. Bartels M, Hudziak JJ, Boomsma DI, et al. A study of parent ratings of internalizing and externalizing problem behavior in 12-year-old twins. J Am Acad Child Adolesc Psychiatry 2003;42:1351-9.

10. Bartels M, van den Oord EJ, Hudziak JJ, et al. Genetic and environmental mechanisms underlying stability and change in problem behaviors at ages 3, 7, 10, and 12. Dev Psychol 2004;40:852-67.

11. Saudino KJ. Behavioral genetics and child temperament. J Dev Behav Pediatr 2005;26:214-23.

12. van der Valk JC, Verhulst FC, Stroet TM, et al. Quantitative genetic analysis of internalising and externalising problems in a large sample of 3-year-old twins. Twin Res 1998;1:25-33.

13. Barker DJ. Fetal origins of coronary heart disease. BMJ 1995;311:171-4.

14. Barker DJ, Hales CN, Fall CH, et al. Type 2 (non-insulin-dependent) diabetes mellitus, hypertension and hyperlipidaemia (syndrome X): relation to reduced fetal growth. Diabetologia 1993;36:62-7.

15. Mick E, Biederman J, Prince J, et al. Impact of low birth weight on attention-deficit hyperactivity disorder. J Dev Behav Pediatr 2002;23:16-22.

16. Indredavik MS, Vik T, Heyerdahl S, et al. Psychiatric symptoms in low birth weight adolescents, assessed by screening questionnaires. Eur Child Adolesc Psychiatry 2005;14:226-36.

17. Lahti J, Raikkonen $\mathrm{K}$, Kajantie $\mathrm{E}$, et al. Small body size at birth and behavioural symptoms of ADHD in children aged five to six years. $J$ Child Psychol Psychiatry 2006;47:1167-74

18. Linnet KM, Wisborg K, Agerbo E, et al. Gestational age, birth weight, and the risk of hyperkinetic disorder. Arch Dis Child 2006;91:655-60.

19. Schlotz W, Jones A, Godfrey KM, et al. Effortful control mediates associations of fetal growth with hyperactivity and behavioural problems in 7- to 9-year-old children. J Child Psychol Psychiatry 2008; $49: 1228-36$

20. Rodriguez A. Maternal pre-pregnancy obesity and risk for inattention and negative emotionality in children. J Child Psychol Psychiatry 2010;51:134-43.

21. Rodriguez A, Miettunen J, Henriksen TB, et al. Maternal adiposity prior to pregnancy is associated with ADHD symptoms in offspring: evidence from three prospective pregnancy cohorts. Int $J$ Obes (Lond) 2008:32:550-7.

22. Van Lieshout RJ. Role of maternal adiposity prior to and during pregnancy in cognitive and psychiatric problems in offspring. Nutr Rev 2013;71(Suppl 1):S95-101.

23. Van Lieshout RJ, Taylor VH, Boyle MH. Pre-pregnancy and pregnancy obesity and neurodevelopmental outcomes in offspring: a systematic review. Obes Rev 2011;12:e548-59.

24. NICE. Dietary Interventions and physical activity interventions for weight management before, during and after pregnancy. National Institute for Health and Clinical Excellence, 2010.

25. Van Lieshout RJ, Schmidt LA, Robinson M, et al. Maternal pre-pregnancy body mass index and offspring temperament and behavior at 1 and 2 years of age. Child Psychiatry Hum Dev 2013;44:382-90.

26. Goldsmith HH. A zygosity questionnaire for young twins: a research note. Behav Genet 1991;21:257-69.
27. Price TS, Freeman B, Craig I, et al. Infant zygosity can be assigned by parental report questionnaire data. Twin Res 2000;3:129-33.

28. Achenbach TM, Rescorla LA. Manual for the ASEBA peschool forms and profiles. Burlington, VT: University of Vermont, Research Center for Children, Youth and Families, 2000.

29. Neale MC. MX: statistical modelling. Richmond, VA: Department of Psychiatry, Medical College of Virginia, 1999.

30. Stata Statistical Software [program]. College Station, TX: Stata Corp LP, 2009.

31. Sourander A, Pihlakoski L, Aromaa M, et al. Early predictors of parent- and self-reported perceived global psychological difficulties among adolescents: a prospective cohort study from age 3 to age 15. Soc Psychiatry Psychiatr Epidemiol 2006;41:173-82.

32. Eaves LJ, Silberg JL, Meyer JM, et al. Genetics and developmental psychopathology: 2. The main effects of genes and environment on behavioral problems in the Virginia Twin Study of Adolescent Behavioral Development. J Child Psychol Psychiatry 1997;38:965-80.

33. Pierce EW, Ewing LJ, Campbell SB. Diagnostic status and symptomatic behavior of hard-to-manage preschool children in middle childhood and early adolescence. J Clin Child Psychol 1999;28:44-57.

34. Van Lieshout RJ, Robinson M, Boyle MH. Maternal pre-pregnancy body mass index and internalizing and externalizing problems in offspring. Can J Psychiatry 2013;58:151-9.

35. Bluher S, Mantzoros CS. Leptin in reproduction. Curr Opin Endocrinol Diabetes Obes 2007;14:458-64.

36. Chan JL, Mantzoros CS. Role of leptin in energy-deprivation states: normal human physiology and clinical implications for hypothalamic amenorrhoea and anorexia nervosa. Lancet 2005;366:74-85.

37. Brennan PA, Grekin ER, Mednick SA. Maternal smoking during pregnancy and adult male criminal outcomes. Arch Gen Psychiatry 1999;56:215-19.

38. Ceddia RB. Direct metabolic regulation in skeletal muscle and fat tissue by leptin: implications for glucose and fatty acids homeostasis. Int J Obes (Lond) 2005;29:1175-83.

39. Hendler I, Blackwell SC, Mehta SH, et al. The levels of leptin, adiponectin, and resistin in normal weight, overweight, and obese pregnant women with and without preeclampsia. Am J Obstet Gynecol 2005;193(3 Pt 2):979-83.

40. Udagawa J, Hatta T, Hashimoto R, et al. Roles of leptin in prenatal and perinatal brain development. Congenit Anom (Kyoto) 2007;47:77-83.

41. Paz-Filho G, Wong ML, Licinio J. The procognitive effects of leptin in the brain and their clinical implications. Int $J$ Clin Pract 2010;64:1808-12.

42. Eyles D, Brown J, Mackay-Sim A, et al. Vitamin D3 and brain development. Neuroscience 2003;118:641-53.

43. Ornoy A. Growth and neurodevelopmental outcome of children born to mothers with pregestational and gestational diabetes. Pediatr Endocrinol Rev 2005:3:104-13.

44. Van Lieshout RJ, Schmidt LA, Robinson M, et al. Maternal pre-pregnancy body mass index and offspring temperament and behavior at 1 and 2 years of age. Child Psychiatry Hum Dev 2012;44:382-90.

45. Ackerman BP, D'Eramo KS, Umylny L, et al. Family structure and the externalizing behavior of children from economically disadvantaged families. J Fam Psychol 2001;15:288-300.

46. Shaw DS, Winslow EB, Flanagan C. A prospective study of the effects of marital status and family relations on young children's adjustment among African American and European American families. Child Dev 1999;70:742-55.

47. Gross HE, Shaw DS, Moilanen KL. Reciprocal associations between boys' externalizing problems and mothers' depressive symptoms. $J$ Abnorm Child Psychol 2008;36:693-709.

48. Burke JD, Loeber R, Birmaher B. Oppositional defiant disorder and conduct disorder: a review of the past 10 years, part II. J Am Acad Child Adolesc Psychiatry 2002;41:1275-93.

49. Vernon MM, Young-Hyman D, Looney SW. Maternal stress, physical activity, and body mass index during new mothers' first year postpartum. Women Health 2010;50:544-62.

50. Rubin $\mathrm{KH}$, Hastings $\mathrm{P}$, Chen $\mathrm{X}$, et al. Intrapersonal and maternal correlates of aggression, conflict, and externalizing problems in toddlers. Child Dev 1998;69:1614-29.

51. Campbell SB. Behavior problems in preschool children: a review of recent research. J Child Psychol Psychiatry 1995;36:113-49. 